\title{
Cultural Differences on Chinese and English Idioms of Diet
}

\author{
and the Translation
}

\author{
Chunli Yang \\ School of Foreign Languages, Zhengzhou University \\ 100 Science Avenue, Zheng Zhou High Technology District, Zhengzhou 450001, China \\ E-mail: Sunday1979@126.com
}

\begin{abstract}
Idioms is a special culture which is shaped in the daily lives of the local people, particularly the idioms of diet has a close relation with various elements, such as the eating custom, history, fairy tales, geographic situations. Also, different ways of translation on different diet idioms in English and Chinese will be analyzed in this article. As a result, it will be very important to know the great culture contents in the idioms of diet in order to do a better job in the research of cross-culture communication and the translation.
\end{abstract}

Keywords: Idioms, Cross-culture communication, Translation, English, Chinese

\section{Introduction}

Idioms are shaped in a community after a long period's living of the local people, and it is the reflection and expression of the culture of a certain race, because of this, the differences on geography, history, custom and living habits will be reflected in the word-using in idioms especially in the idioms of diet. Using idioms when speaking is a usual way for the local people to express their ideas clearly and lively to others from another nation, so in the course of cross-culture communication, it is an important thing to use them correctly in order to make us better understood by the people with different cultural backgrounds. Unfortunately, only the people who are very good at speaking that kind of language can use adequately and to the point use idiomatic expressions in their speech, and the reason is that most of the time, people know little about the history and the culture behind these idioms. Some scholars point out that idioms are often colloquial metaphors---terms which require users to have some foundational knowledge, information, or experience, to use only within a culture where parties must have common reference. As the development of new technology and the shape of the global country, the need of strengthening conversation between different nations becomes more and more urgent. But the research in such a field is still limited and only during recent twenty years more scholars began to pay attentions to the field of folk-custom and contact this with the cross-culture communications research, but recent researches always combine all idioms together without any logical and systematic convey and classification. The following contents will start from the diet idioms in both Chinese and English, and set up a basis in order to introduce more idioms to the people with different cultural backgrounds, this part includes large numbers of idioms which contain words that are used to describe food and the reasons which lead to the differences of word-using in the two languages, besides this, many examples are used to prove these opinions.

\section{The Difference of Word-Using in Diet Idioms Related With People's Eating Habits in English and Chinese}

In most languages, idioms are created by the laboring people and the local people during their daily life, so naturally, the words that describe the necessities people use or the food they eat are used frequently in idioms. Because of the special living conditions and the geographical situations, the western people like eating the food that can provide them enough energy, calories and high nutritious. Meat is the favorite food of the English people, they prefer beef, mutton, chicken, and game meat, but eat less pork than Chinese people, for Islamism is one of their major religion, and people from such a group refuse to eat pork. They are used to preparing fruits in every meal, and they also like drinking wines such as beer, grape wine and liquor. Toasted bread is made as their main course, and if there are pudding, soup, ham and fresh vegetables, that would be a wonderful dinner. Except various wines, the western people also like drinking milk and tea. They even make such a kind of habit as a part of their life. They like to drink the black tea from China but the way of drinking is different from the Chinese people. Fixed time is one of their characters in every afternoon; English people will choose a suitable place and enjoy the beautiful afternoon with some friends under the warm sunshine with a cup of mixed milk-tea. All of these eating habits have a close relation with the particular geographical conditions. The Great Britain is an island country with large area of oceans around, and the warm temperature and marine climate make this place good for the growth of the grass, and for the development of stockbreeding. Because of the long coastline of England, their lives can not be kept without the Marine Fisheries. The fast pace of the modern life makes the fast food popular in American's life. Hamburgers and hotdogs can be found in every restaurant and snack 
stall with steaks, fried chicken, seafood and salad. After every meal, dessert will be prepared, and this part always contains: apple-pie, cheese cake, chocolate, ice-cream, sundae and so on.

In china, rice and wheat are considered the materials for the main course. Their interests are on the taste of food, so the kinds of dished and cooking techniques are various, such as pan-frying, stir-frying, quick-frying, deep-frying, stewing, and smoking. These differences reflect on the use of words in idioms. These words not only can be used to describe food but also own the characteristic of a certain nation. That is to say, these words not only own their conceptual meaning, but also have abundant figurative meaning and reflected meaning.

\subsection{The Favorite Food of the Western People and the Related Idioms}

\subsubsection{Idioms Which Contains "Bread"}

Like rice in the life of the Chinese, bread also plays a very important way in the western people's daily life; so there are large numbers of idioms that contains the word "bread", such as:

\section{A. Bread and Butter}

The meaning of this idiom is the way of somebody to earn his living, and the second meaning is "common things". For example: It is a bread and butter diamond. It means a common diamond. Although there are differences between the two meanings, they are still very similar. But it is not always used that way; a bread-and-butter letter is no longer a common letter but a kind of letter to show the thanks of the guests to the host's warm reception.

\section{B. Earn One's Bread}

This idiom has the same meaning as "earn one's living", for example: He now earns his bread by doing odd jobs.

C. Hope is poor man's bread.

The initial meaning of this sentence is that if a poor man wants to survive he should not give up his hope toward life.

\subsubsection{Idioms Which Contains "Butter"}

Butter is also a necessary part in the meal of the western people. Except the examples listed above, there are other expressions, like:

\section{A. Butter Up}

This idiom means to praise or flatter somebody excessively to try to change someone's mind by doing things for him or her and being really nice so he or she will do what they want. This saying comes from the simple act of buttering a piece of plain bread which is like making it look and taste better, this is the same as flattering a person, for example: He began to butter up the boss in hope of being given a better job. But "to butter up somebody" means to entrap or ensnare someone. The two meaning of the idiom is contrary to each other.

\subsubsection{Idioms Which Contains "Potato"}

The custom of eating potato in America has been kept for a long time and that can be dated to the foundation of the country. Although it is said that potato is originally planted in Holland, it has already become a part of English. In the colonial period, the culture of potato has also been passed to America. As a result, the Americans also express their interests on potatoes in idioms:

A. "A hot potato" refers to a trouble or a difficult problem which can not be solved easily. The meaning can be easily understood from the image described in the idiom.

B. "A big potato" is used to describe an important person.

C. "A couch potato" is used to describe a kind of person who lives a life with minimum effort or an inactive TV addict. Television was invented in the 1940s'; this idiom dates from the 1970's, and has a close relation with the television. Some people say that because the Americans like keeping themselves in the sofa and eating potato chips when they were watching TV.

\subsubsection{Idioms Which Contain "Cheese"}

"He is a big cheese in the company" means he takes an important part in the company.

"My brother and I are as different as chalk and cheese" means my brother and I are completely different from each other, because cheese and chalk are apparently two different kinds of things.

\subsubsection{Idioms Which Contain "Egg"}

The daily life of housewives is trivial and ordinary, but the idioms they created are not less good than those by their husbands, as they have convenient access to the colorful grassroots of life and they have rich experience of household life. 


\section{A.” Over-Egg the Pudding"}

It is to spoil something by trying too hard to improve it. To add too many eggs to a pudding, or even to add more to the instant cake makes it unnecessary, is to go too far, to be excessive, hence the current meaning of "to exaggerate", for example:

As a director, I think he has a tendency to over-egg the pudding with a few too many gorgeous shots of the countryside.

\section{B .An Egg-Head}

This idiom comes from the ancient Greece story and it refers to the intellectual people, for in English, "egg" is usually used to express the positive meaning.

Except above, people use "Good Egg" to describe a good person and "golden eggs" means great benefits.

\subsubsection{Idioms Which Contain "Cake"}

Western people like cooking and baking different deserts, which not only reflect their eating habits but also their high quality lives.

\section{A. A Piece of Cake}

It means it is easy to solve the problem.

B. "Take the Cake" means to be the best or to be the first. For example:

I have heard of a lot of crazy stories, but this one takes the cake.

C. To have one's cake and eat it.

This idiom means "to have the advantages of two things which contradict each other". This saying first turned out in the proverbs collected by John Heywood. The cake will disappear after one eats it, and it is impossible to keep it and eat it at the same time. This saying can be seen in many languages like in French, people will use "you can not have the cloth and keep the money" to replace that, for the modern and fashionable cloth is the unique character of France, and in Italy, they will ask: "Do you want to eat your cake and still have it in your pocket?". These expressions can also reflect that: behind every idiom, there are different histories and cultures of different nations.

\subsubsection{Idioms Which Contain "Cream" and "Cheese"}

The developing and advancement of animal husbandry in English-speaking countries make milk products popular in these countries, and this is also reflected in idioms.

\section{A. Cream of the Crop}

It means the outstanding people or the best of everything. Cream rises to the top, and the top is associated with the best. And cream is considered the best part of un-homogenized milk. For example:

We are looking to hire only the cream of the crop.

\section{B. A Big Cheese}

It means an important person but it is usually said sarcastically. Some cheese has a very noticeable smell. A big cheese will be noticeable. The sarcasm comes from the fact that the smell is sometimes unpleasant. For example:

If you want a raise in pay, you have to be nice to the big cheese.

\subsubsection{Peanuts}

In the United States, you can buy lots of peanuts for a dollar, so each peanut is worth very little. That is why this idiom means be a very small amount of money.

For example:

I am glad that you worked hard all summer selling lemonade and saved five hundred dollars, but to be honest, that is peanuts when it comes to paying for your college education.

\subsubsection{Idioms Which Contain "Salt"}

Salt was an expensive necessity in the past time, and it is also an indispensable sauce in the meal. In the middle ages, in the upstream society, if the host invited guests to have dinner at home, they would put the salt pot in the right middle of the table, and ask the honored guest to sit in front of the salt pot in order to show his or her respect. Others would sit on the sides of the long table.

\subsubsection{Idioms Which Contain "Milk"}

A. "Cry over spilled milk" means to be regretful to the fault that you made but you can not change the result. For example: 
I really feel regretful about it now, but there is no use crying over spilled milk.

B. "Milk and Water" means boring things and persons. It has the same meaning as "the Plain Water" in the Chinese saying. The difference between the two languages is decided by the different living style of the two races.

\subsubsection{Idioms Which Contain "Fish"}

From the ancient time till now, people who live in the countries on the sea depend on the fishing industry, most of their living resources are fish. So idioms containing fish are many:

A. Every little fish would become a whale.

This sentence is used to encourage people to become a successful man.

B. Cut no fish till you get them.

C. Never offer to teach fish to swim. This idiom has the same meaning as the Chinese idiom "ban men nong fu".

D. Who would catch fish must not mind getting wet.

E. A Big Fish in A Small Pond.

This saying also has the similar meaning in Chinese and the difference is that they compare people with different animals, for example: the English sentence, "She was the kind that would rather be a big fish in a small pond" can be translated to "Ta shi na zhong ning wei ji tou bu zuo feng wei de ren".

\subsubsection{Idiom Which Contain "Wine"}

Western people can not have a dinner without wine, whisky, grape wine, and various beers. These are all their favorite beverages, which can be reflected in idioms.

A. "There are less to every wine". This sentence means nobody is perfect in the world.

B. Wine and wenches empty men's purses.

C. Wine is a turncoat, first a friend, then an enemy.

D. Wine is old men's milk.

E. Wine makes all kinds of creatures at table.

F. Wine and judgment mature with age.

G. Bacchus hath drowned more men than Neptune.

In this sentence, Bacchus is the Roman name for Dionysus, god of wine, son of Zeus and Semele, a daughter of Cadmus. Neptune is the name of the god of sea in the Roma mythology, so this sentence can be translated directly as "wine drowned more men than the ocean".

$\mathrm{h}$. In wine there is truth.

\subsection{The Words of Diet Used in Chinese Idioms}

Compared with the warm temperate maritime climate of the Great Britain, the continental climate of China makes it an agricultural country. Because of the particular national conditions, the large numbers of people and the shortage of average natural resources make the need for food more urgent. Grains are planted in abundance in all directions of the whole country, among them, corns, wheat, rice are the most popular ones. Although meat, especially pork is Chinese people's favorite food, the expensive price can not be accepted by most of the people in the past. As a result, the kinds of dishes are abundant, and the shortage of food makes the Chinese people explore their intelligence and invented many cooking methods to cook food, which make Chinese dishes famous both at home and abroad.

\subsubsection{Rice}

The importance of rice in China can be compared to bread in English. It is the main course in almost every meal of all the families especially in the southern part of China. There are a lot of idioms which contain the symbol of "rice", that is "mi" in Chinese, such as:

\section{A. Qiao fu nan wei wu mi zhi chui}

It means no matter how clever a housewife is, she can not cook without materials.

B. Bu wei wu dou mi zhe yao

It is used to describe a person who never gives up his principles to be a better man when he is faced with benefits.

C. Bai yang mi yang bai yang ren

It means everyone is different in their minds, appearances and the way they treated others. 


\subsubsection{Other vegetables}

Except rice, Chinese people also like eating vegetables, bean curd, lotus root, and sauce, so the idioms of diet are:

\section{A. Dao zi zui, dou fu xin}

It means although the person likes scolding others, actually he is a kind man. For example: Although his mouth is sharp as the knife, his heart is soft like the bean curd.

\section{B.Huang hua cai dou liang le}

It means everything is late, "huang hua cai " is a kind of vegetable which is common in Chinese dishes, but here it is a metaphor, and it is compared to somebody or something which is late to do something or which is delayed and can not be solved any more.

\section{C .Luo bo bai cai, ge you suo ai}

In this sentence there are two common vegetables, and it is traditionally used to talk about people who have different opinions and could not agree with the others. But it is usually translated as "every man has his hobbyhorse", which can not be directly translated to "everyone loves his cabbage and radish".

\section{Ou duan si lian}

In Chinese literature works, authors choose this idiom to describe a special relationship between two people, especially a man and a woman who still keeps contact with each other after they break up. "ou"is a kind of vegetable planted in the south of china, the character of it is when it is cut apart, there are still fiber connect each part of it. In translation, it can not be translated directly into "lotus root" because it is not familiar to the western people.

\section{Different Ways of Translation on Different Diet Idioms in English and Chinese}

\subsection{Finding the Same Structure in English and Chinese Idioms}

\subsubsection{Completely Similar Structures}

\section{A. Idioms Which Have the Same Structure but Can Not Be Translated Directly}

\section{a. "Kill the Goose" that Lays the Golden Eggs}

At the first sight of this idiom, if you are familiar with Chinese idioms, it is easy to find the sentence that has the same structure in Chinese that is "sha ji qu luan", except this, by considering the habit of word-using of the western people, it can be easier for you to understand the meaning of the phrase or sentence, because the word "goose" in English always has the same meaning as "chicken" in Chinese.

b. "A Piece of Cake" can be easily translated into "xiao cai yi die" if you know

this Chinese idiom and the Chinese culture on dishes and diet.

c. "As a man sows, so shall he reap"

This idiom can be translated into "zhong gua de gua, zhong dou de dou". In both of English and Chinese there are similar expressions, so it is easy to translate this kind of idioms.

d. In the idiom "to have one's cake and eat it" can be translated into "yu yu xiong zhang liang zhe jian de" for in Chinese idiom here is a saying: "yu yu xiong zhang bu ke jian de". The meaning is when you are in such a condition, you must choose one and give up the other one .They both have the same meaning. But in most of the time, because of the great differences in English and Chinese culture we can not always find the idioms which have both similar structures and similar meanings, For example: From the structure of the idiom "one cannot make a silk pure out of a sow's ear" people will at once find an idiom which has the same structure in Chinese, that is "qiao fu nan wei wu mi zhi chui ", but in the following sentence, you will find problems:

What is the use of a scholarship to that boy? He will never be a gentleman; you might as well try to make a silk purse out of a sow's ear.

In this sentence, the meaning of this idiom is "you cannot make something good of what is by nature bad or inferior in quality". Apparently, "sow's ear" refers to "bad material", and silk purse refers to good things, so the Oxford Dictionary translate this idiom into "huai cai liao zao bu chu hao dong xi" which means one can not make productions with good quality from bad materials. On this point it has the similar meaning with the Chinese saying, "xiu mu bu ke diao".

\section{B. Idioms Which Has the Same Structure And The Same Figurative Meaning}

This kind of idiom takes a little part in languages. They have the same structures and the same figurative meaning, so translating them directly not only can make the readers understand but also does well for keeping the original style of the material. For example, "tang yi pao dan" can be translated directly into "sugar-coated bullets" and "sour grapes" can be translated directly into "suan pu tao", and the peculiar reason is that because of the communication between the 
western and eastern, some new words are introduced from one country to another and become one part of the local people as time passes by.

\subsection{Idioms Which Have Not Similar Structures}

Except above idioms, there are also idioms in English which have not the corresponding sayings in Chinese idioms, so we should translate them indirectly by using other words we usually use to express such ideas, for example, "Above the salt". From the literal meaning no one knows the figurative meaning of it, and we must know the idiom comes from an ancient story related to the eating custom of the middle age English people, and the habit of putting salt in front of honored people, so the meaning is being in a position of honor, when we translate the idiom we can say "bei zun wei shang bin".

Another example is "spill the beans" which means to reveal or make known a secret or a piece of information, only translating the literal meaning will make people confused and cause troubles, so we can refer to the source of the idiom and found it come from an ancient Greek story about their selection system, as a result, it can be translated into "to make known a secret".

\subsection{Translation Methods from Chinese to English}

3.2.1. Find the same structure in English, and change the improper word to the one they used to use, for example:

"ning wei ji tou, wu wei niu hou"is one of the popular Chinese idioms, but in English, "chicken" is always used to describe a coward man, in Chinese, "ji tou" has the positive meaning, and in English "dog" has a positive meaning, so this idiom should be translated as "better be the head of a dog than the tail of a lion".

The same case also happens in the idiom, "gua yang tou mai gou rou", it used to be translated as "cry up wine and sell vinegar" or "offer chaff for grain".

3.2.2. When the literal meaning is not used as frequent as its figurative meaning.

Idioms should be added the figurative meaning after the literal meaning when translation.

For example, "jiang hai shi lao de la" can be translated as "The old ginger is spicy". And then add "older people have more experienced" after that.

\section{Conclusion}

As an important part in languages, idioms take the heavy responsibility of spreading culture and put forward the civilization of a nation or a community. Each idiom contains a small part of the customs of the local people. This article sets a sight from the angle---the idiom which contains words of diet as an introduction of large numbers of idioms in both English and Chinese, to show the different cultures behind them and the different values reflected by these idioms.

These differences are decided by the history background, different living habits and customs, even the geography environment, and their particular climates and reflected in every aspect in their lives. Language absolutely is not an exception. Idioms are largely shaped by the laboring people when they are working, in order to understand them, we should have enough knowledge about their daily life, their history and their customs. Another source is the influences from other country which contains the introduction of costume, festival, food, word, language and so on. The influence also comes from different religions, as Christ is the major religion in England and many other idioms came from the bible. Except above, idioms are also influenced by some mythologies in the ancient time, like the Greek mythology and Aesop's Fables. Chinese idioms are the same. Some words come from their daily life and some of them from the fairy tales and the long history. As the need of communication become more and more urgent between countries in the world, the exchange of culture and knowledge is also an important mission.

Translation is a proper way of spreading culture to other countries, and the translation on idioms is no doubt a good action to put this idea into practice, for translation, enough knowledge of the history, geography, custom is necessary, what is more important is the skills of translation, we not only should express the ideas exactly to the both sides, but should master methods on translation, making translation a kind of art , except carrying forward the fine traditions of the former translators in this field, like keeping the principles on translation : keeping the style of the original material, expressing the original idea of the author of the original text, and keeping to the fact, later translators should make more efforts to summarize their own translation skills from their practices and experiences. Only by sticking to the translation principles and deep study and research on the culture can make idiom a more effective medium in the course of cross-culture communication.

\section{References}

Authony Esler. (1994). The western world, volume 2. New Jersey: Prentice-Hall, Englewood Clifts.

David A. Thayne. (2002). Easy English expressions for everyday use. Beijing: New World Publishing House.

Hands Penny. (1996). Chambers English dictionary of idioms. Prentice Hall, Inc. 
Procter Paul. (1995) Cambridge international dictionary of English. Cambridge: Cambridge University Press.

William Hughes. (1993). Western civilization, volume 1. Guilford: The Dushkin Publishing Group.

Chen Wenbo. (2005). A comparative study of English and Chinese idioms. Beijing: The World Knowledge Press.

Chen Wenqian. (2005). The story behind English idioms. Haikou:Nan Hai Publish House.

Hou Ninghai. (2008). Popular English phrases and idioms. Nanjing: Nanjing University Press.

Jiang Lei. (2002). The cultural comparison between English and Chinese idioms. Wuhan: Wuhan University Press. 